\title{
ATMOSPHERIC PHENOLIC DERIVATIVES AS TRACERS IN AN URBAN AREA
}

\author{
MARÍA A. RUBIO ${ }^{*}$, PATRICIA BUSTAMANTE ${ }^{1}$, YEANICE VÁSQUEZ P. ${ }^{2}$

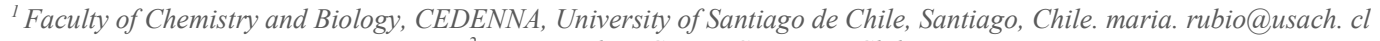 \\ ${ }^{2}$ Mario Molina Center, Santiago, Chile
}

\begin{abstract}
The screening of certain chemical markers associated with the burning of fuels (gasoline, diesel, firewood, pellets, and kerosene) is carried out. The studied markers correspond to phenolic compounds present in emitted gases. Identification and quantification were performed by solid phase extraction followed by highperformance liquid chromatography with diode-array detection (HPLC-DAD). The volatile phenolic derivatives detected and quantified in these experiments were phenol $(\mathrm{Ph}), 2$-nitrophenol (2-NPh), 4-nitrophenol (4-NPh), o-hydroxyphenol (2-HPh), 2-methoxyphenol (2-MetPh), 4-methoxyphenol(4-MetPh) and 2,4dinitrophenol.

The emissions from firewood- and pellet-burning heaters contain mainly o-hydroxyphenol, 4-methoxyphenol, and Ph. In the emissions from gasoline-powered vehicles, only $\mathrm{Ph}$ was detected, and in those of diesel-powered vehicles, only 2-NPh and 4-NPh were detected. Kerosene-burning heaters did not exhibit measurable amounts of phenolic compounds in their emissions. The controlled irradiation of the emissions from the burning of firewood and pellets using a photochemical camera showed high degrees of stability of these compounds. The studied phenolic derivatives did not photolyse or were not formed by the photochemical pathway; therefore, their origin is clearly primary, which allows their use as combustion tracers in a particular atmosphere. The presence of Ph derivatives in the Santiago atmosphere indicates the existence of mobile sources (daytime) and the use of firewood (night-time). The presence of 2-NPh and 4-NPh derivatives in the air would be strongly associated with the use of mobile sources that use diesel. In contrast, catechol is associated with the burning of wood forheating.
\end{abstract}

Keywords: phenolic derivatives, biomass, combustion tracers

\section{INTRODUCTION}

Phenols (Phs) and nitro phenols are among the most ubiquitous families of compounds present in air (gas phase and/or particles) ${ }^{1-5}$ in clouds, ${ }^{6}$ rain,${ }^{7-9}$ surface water, ${ }^{10,11}$ fog ${ }^{12}$ and dew. ${ }^{13}$ Nitrophenols are present in most systems ${ }^{14}$ at high concentrations, and furthermore, the number of compounds present at lower concentrations or only in certain samples is very large. ${ }^{\mathbf{8} 14,15}$ Interest in these compounds has arisen due to their toxicity, ${ }^{16,17}$ and the compounds are usually of primary and secondary origins through a variety of processes that contribute to their formation and removal. ${ }^{11}$ This rich and complex chemistry in the gas phase and in water drops and particles ${ }^{18,19,20}$ makes it difficult to evaluate the sources ${ }^{18,21,22}$ and removal processes. ${ }^{7}$ Furthermore, the importance of these processes is dependent on the compound that is being considered, the sampling site, and the prevailing conditions ${ }^{23}$ However, most studies have concluded that automobile exhaust emissions are one of the most important factors that contribute to the presence of $\mathrm{Ph}$ derivatives in polluted urban environments. ${ }^{24,25,26}$

Santiago, Chile, is a highly polluted city in which $\mathrm{Ph}$ and numerous compounds derived from nitrophenols have been detected in the downtown area, both in the air and in dew. ${ }^{13}$ The daily pattern shows a substantial increase in the concentrations of $\mathrm{Ph}$ and 2-nitrophenol (2-NPh) in air during the peak hours from 08:00 to 12:00, indicating a significant contribution of the emissions of mobile sources in the city. Firewood burning is currently a source of pollution in the city of Santiago, which is associated with its availability and cost. Biomass burning represents a significant source of organic aerosols at a global scale,${ }^{27}$ and depending on the elapsed time, biomass burning dominates the primary or secondary mass contributions. ${ }^{28}$ At the local scale in Chile and its cities located in the south (beyond $30^{\circ} \mathrm{S}$ ), biomass is one of the most widely used fuels for cooking and heating, playing a fundamental role in indoor and outdoor air pollution, particularly in cold weather. Although many efforts have been made to quantify the overall source inventories, success has been limited due to the wide range of materials such as different woods, pellets ${ }^{29,30}$ and heating/cooking appliances employed. ${ }^{31,32} \mathrm{Yu}$ et al. $(2013)^{33}$ and Yee et al. $(2013)^{29}$ measured wood burning emissions from various fireplaces and found that the emissions varied with the kind of fuel consumed and the fireplace design. Methoxyphenols significantly contribute to the emissions from traditional firewood burning and, to a lesser degree, to those from pellet burning. ${ }^{34}$ Above $800{ }^{\circ} \mathrm{C}$, methoxyphenols are decomposed, a process that contributes to the emission of carcinogenic polycyclic aromatic compounds. Aromatic compound photolysis, particularly under high NOx conditions, leads to the production of nitrophenols. Often, NOx levels are linearly correlated with the amount of nitrogen in the fuel, ${ }^{34}$ and nitric acid is the main nitrogen deposit. ${ }^{36}$

In a sampling campaign conducted in winter, Yuan et al. (2016) ${ }^{37}$ reported daily nitro phenol profiles with maximum concentrations at night, which were most likely due to the emissions from heaters during the night. However, gas phase oxidations contribute to the production of these nitrophenols. ${ }^{2}$

The aim of this article is to characterize the emissions and presence of phenolic derivatives from different atmospheric pollution sources present in Santiago. The compounds of interest that will be used as possible markers of combustion from different sources used in Chile are Phs, nitrophenols, quinones, catechols (hydroxylated derivatives), and cresols (methylated derivatives). Sampling was conducted from engines using gasoline and diesel and from the heaters used most widely for heating in Chilean homes. Likewise, the levels of these compounds in the atmosphere and dew water of central Santiago were evaluated. The study of dew water represents removal by dissolution of the semivolatile phenolic derivatives present in the soluble fraction of the particulate material or the diffusion of these substances in the condensed phase.

This study is justified because the markers proposed in numerous works are fine particulate matter $\left(\mathrm{PM}_{2.5}\right)$ or its constituents, such as levoglucosan or polycyclic aromatic hydrocarbons (PAHs), which are especially present in burned biomass (wood and pellets) emissions.

This study determined the presence and stability of certain markers associated with the burning of firewood, gasoline and diesel in a city with different energy matrices (residential heating to firewood and vehicular traffic) and under atmospheric oxidizing conditions.

\section{MATERIALS AND METHODS}

\subsection{Sampling}

Gas samples were taken directly A) from the exhausts of two engines, namely, a 2011 Toyota Yaris model gasoline engine and a 2012 Citroën Berlingo 1.6 HDI diesel engine; B) from the outlet of a firewood stove using Eucalyptus, Hualle, and Pellin firewood with medium air inlet control and from the outlet of a stove with the controlled burning of firewood using only Eucalyptus; C) from an automatic stove with the controlled burning of Pine pellets; D) from closed environments heated only with kerosene stoves; and E) from the atmosphere over an eastern downtown location in Santiago.

In all of the samples, the gases were led under controlled flow through $\mathrm{Si}(\mathrm{OH})$ cartridges that selectively retained the nitrated organic compounds (Licrolut, MERCK). These cartridges were subjected to washing and drying processes before sampling and were then eluted with high-purity methanol and acetic acid (1\%). ${ }^{14,38}$ The sampling times varied according to the type of source: for the samples from exhaust pipes, the gases were introduced for $10 \mathrm{~min}$ at a flow rate of $10 \mathrm{~L} \mathrm{~min}^{-1}$. In the samples from the output ducts of firewood and 
pellet stoves, the sampling time was $15 \mathrm{~min}$. The environments heated with kerosene stoves were sampled for 3 hours, and the sampling of atmospheric air lasted 3 to 8 hours. A Dryfast $210 \mathrm{C}-02$ Welch vacuum tech pump with a flow rate of $10 \mathrm{~L} \mathrm{~min}^{-1}$ was used for all of the samplings.

\subsection{Heating devices}

A Wamsler firewood stove weighing $86 \mathrm{~kg}$ with a nominal heating power of $6.5 \mathrm{~kW}$ and an energy yield of $78 \%$ was used. Firewood consumption occurred at a nominal power of $1.85 \mathrm{~kg} / \mathrm{h}$ with a double dilution system consisting of primary air and secondary air and a $15 \mathrm{~cm}$ diameter outlet duct. The volume to be heated was $132 \mathrm{~m}^{3}$.

\section{The RIKA brand, MEMO model pellet stove weighed $110 \mathrm{~kg}$.}

The nominal heating power was $2.4-9 \mathrm{~kW}$ depending on the program being used, and the energy yield was $92.1 \%$. Firewood consumption occurred at a nominal power of $2.2 \mathrm{~kg} / \mathrm{h}$, and the volume to be heated was $50-240 \mathrm{~m}^{3}$. The outlet duct diameter was $12.5 \mathrm{~cm}$

A Toyotomi kerosene stove, model LC-43, with laser technology was used, with a maximum power of $4.187 \mathrm{~W}$, tank capacity of $7.6 \mathrm{~L}$, and consumption level of $0.109-0.406 \mathrm{~L} / \mathrm{h}$. The Sindelen kerosene stove, model Sunnymet EP6500 , with a wick, had a power of $2.984 \mathrm{~W}$, tank capacity of $5.7 \mathrm{~L}$, and consumption level of $0.29 \mathrm{~L} / \mathrm{h}$.

\subsection{Controlled flow chamber}

The chamber system was designed and developed at the Harvard T.H. Chan School of Public Health (HSPH) in Boston, Massachusetts, USA. A wooden enclosure was built adjacent to the heating devices. For more details, see Gramsch et al. (2018). ${ }^{39}$

\subsection{Atmosphere of Santiago}

Atmospheric air samples and dew water samples were taken at a sampling station located in the eastern area of downtown Santiago (LAT: -33.4612045; LONG: $-70.6581573 ; 562 \mathrm{~m}$ a.s.1.), on the university campus. The samples were taken at the time of the highest atmospheric pollution in Santiago during the months of May through July, except on rainy days, during the years 2014, 2015, and 2016. Similarly, a sampling campaign was conducted in January and March of 2016 (summer). At least ten days per year were sampled.

The dew water was collected manually on clean Teflon film, similar to the method described in Rubio et al. (2012)..$^{13,38}$

\subsection{Chemical analysis}

The sampling cartridges were eluted with high-purity methanol $(1 \%$ acetic acid), and this solution was subjected to chromatographic analysis.

The phenolic derivatives were quantified using high-performance liquid chromatography (HPLC), Waters 600, with diode-array detection (DAD) and a C-18 Symmetry column RPC-18 4.6 x $250 \mathrm{~mm}$. A $5 \mathrm{mM}$ phosphate buffer with a pH of 5.5 and acetonitrile (isocratic) were employed as the mobile phases. ${ }^{38}$
The limits of detection used in the chromatographic analysis are related to the minimum area to be measured without error. The limits of detection and the identification of the phenolic derivatives were performed as described in Rubio et al. 2012. ${ }^{13}$ The quantification of the phenolic derivatives was performed by HPLC using certified standard solutions (Ultra-Scientific Products, SigmaAldrich).

\section{RESULTS AND DISCUSSION}

\subsection{Exhaust pipes of a gasoline and a diesel engine.}

It was found that the emitted phenolic derivatives differed completely according to the engine and the fuel used. $\mathrm{Ph}$ was detected only in the gasoline engine's exhaust and not in that of the diesel engine. Additionally, 2-NPh and 4nitrophenol (4-NPh) were detected from the diesel engine but not from the gasoline engine. Table 1 shows the average values obtained $(n=8)$, showing a notable dispersion. However, the values are valid for qualitative purposes. The values were expressed per kilogram of burned fuel (either gasoline ordiesel).

The kind of fuel and the engine model determine the emitted phenolic compounds. This result is not in agreement with what was published previously,${ }^{24}$ where it was noted, in one of the few papers published on this issue that burning gasoline emits 2-NPh and burning diesel emits 2-NPh and 4-NPh.

3.2 Emission of phenol derivatives from the outlet ducts of wood burning heaters.

Analysis of the emitted gaseous volatile or semi-volatile compounds showed that hydroxylated (catechols), methoxylated (guaiacol, mequinol, syringol), and methylated (ortho-, meta-, and para-cresol) derivatives were present in these emissions. Table 1 summarizes these results, showing variations according to the kind of firewood. The concentration values of these compounds, expressed in micrograms per kilogram of burned fuel, are lower for $\mathrm{Ph}$ and methyl phenol.

It was found that the type of firewood conditions the proportions of emitted $\mathrm{Ph}$ derivatives. However, in the emissions of all kinds of firewood, ohydroxyphenol is the predominant compound. $\mathrm{Ph}$ is emitted almost 20 times more from gasoline than from firewood per kilogram of fuel.

The large variability is associated with the combustion process. Combustion is a dynamic process that even under controlled feed conditions presents notable variations. The results show a trend, and the results are not absolute values. If we accept a $50 \%$ variation in the trends, the results are valid.

Phenolic compounds, such as o-hydroxyphenol, phenol, 4-methoxyphenol, 4-methylphenol, and 2,5-dinitrophenol, are the most abundant in the emissions of biomass burning, ${ }^{29,40}$ which is due to the thermal decomposition of lignin in the absence of oxygen. ${ }^{41}$

In our measurements, the phenolic compounds that were found in the highes concentrations were o-hydroxyphenol, 4-methylphenol, and 4-methoxyphenol. This finding agrees with those of previous publications, ${ }^{4}$ which state that these compounds are the main fragments obtained after decomposition or defragmentation of a polymer composed mainly of phenylpropyl alcohols.

Table 1. Concentration $\left(\mu \mathrm{gkg}^{-1}\right)$ and standard deviation values $(\mathrm{n}=8$, ) of phenol and nitrophenols present in emissions from the exhausts of gasoline and diesel engines, and from burning euclyptus, hualle, and pellin wood in double chamber heaters.

\begin{tabular}{|c|c|c|c|c|c|}
\hline & GASOLINE & DIESEL & $\begin{array}{c}\text { EUCALYPTUS } \\
\text { FIREWOOD }\end{array}$ & $\begin{array}{c}\text { HUALLE } \\
\text { FIREWOOD }\end{array}$ \\
\hline Phenol & $8600 \pm 2000$ & ND & $330 \pm 52$ & $294 \pm 9$ & ND \\
\hline 4-Nitrophenol & ND & $342 \pm 130$ & ND & ND & ND \\
\hline 2-Nitrophenol & ND & $460 \pm 180$ & ND & $3720 \pm 840$ & $3726 \pm 1700$ \\
\hline o-Hydroxyphenol & ND & ND & $23000 \pm 19000$ & $1580 \pm 567$ & $28 \pm 7$ \\
\hline 4-Methoxyphenol & ND & ND & $7500 \pm 5000$ & $82 \pm 16$ & $17 \pm 2$ \\
\hline 2-Methoxyphenol & ND & ND & $853 \pm 272$ & $39 \pm 12$ & $20 \pm 11$ \\
\hline 3-Methylphenol & ND & ND & & 2800 \\
\hline
\end{tabular}

ND: no detected 
3.3 Emissions from firewood and pellets under controlled combustion conditions.

In the comparative experiments using heaters with the automatic input of firewood and pellets, the measured $\mathrm{PM}_{2.5}$ emissions of the automatic pellet stove was 2 orders of magnitude lower than those registered for the manual firewood oven, and the emitted phenolic compounds did not show substantial differences. There was a large variability in the emissions of the firewood heaters. It was also verified that the emissions of Phs were 100 times higher in the firewood emissions than in those due to pellet burning.

The results of the comparison of the compounds sampled under the same conditions are shown in Table 2. In these experiments, the emissions are driven to a $14-\mathrm{m}^{3}$ controlled flow chamber, and a sample is extracted from the outlet tube or duct of both heaters. The results are expressed in micrograms of compound per cubic metre.

Table 2. Concentration $\left(\mu \mathrm{gm}^{-3}\right)$ and standard deviation values $(\mathrm{n}=6)$, of phenol and nitrophenols present in emissions from firewood and pellets under controlled combustion.

\begin{tabular}{|c|c|c|}
\hline & FIREWOOD STOVE & PELLET STOVE \\
\hline Phenol & $1.12 \pm 0.69$ & $0.32 \pm 0.11$ \\
\hline 4-Nitrophenol & $\mathrm{ND}$ & $0.09 \pm 0.08$ \\
\hline 2,5-Dinitrophenol & $2.78 \pm 1.34$ & $0.03 \pm 0.02$ \\
\hline 0-Hydroxyphenol & $43.1 \pm 40.6$ & $0.40 \pm 0.22$ \\
\hline 4-Methoxyphenol & $7.60 \pm 7.46$ & $0.91 \pm 0.12$ \\
\hline 4-Methylphenol & $41.8 \pm 41.5$ & $0.09 \pm 0.08$ \\
\hline
\end{tabular}

Large differences were found in the concentrations of the phenolic derivatives emitted from the pellet and the firewood stoves, with differences of two to three orders of magnitude.

The emissions of phenolic derivatives showed a high variability of approximately $50 \%$ in the emissions from the firewood stoves and $10 \%$ in those from the pellet stoves. The high variability is associated with the irregularity of the combustion process, especially for the firewood stove.

The different concentrations are related, as shown above, to the different types of materials, Eucalyptus wood, and Radiata Pine pellets. The technology used in the pellet heater, where the combustion temperatures are higher, leads to a decrease in the low molecular mass organic compounds.

An inefficient combustion with a low oxygen ratio will promote the decomposition of the lignin macromolecule, mainly into simple phenolic compounds. ${ }^{33}$ This phenomenon would explain the difference in the concentrations between the pellet and the firewood stove emissions, with the wood stove emissions being 2 orders of magnitude higher than those of the pellet stoves. The results show a trend and are not absolute values.

The compounds o-hydroxyphenol, 4-methoxyphenol and $\mathrm{PH}$ are the most common phenolic compounds emitted during the combustion of Eucalyptus firewood and Pino radiata pellets. This finding agrees with what has been evidenced by many authors. ${ }^{43,44,45}$

Evaluating the differences between the types of heaters with a confidence level of $95.0 \%$, there is a statistically significant difference between the means, indicating that the samples are from independent origins that must be analysed individually for the studied compounds (test Shapiro-Wilks and UMannWhitney $)^{46,47}$

Normalization of the data for the $\mathrm{Ph}$ concentration (data not shown) indicates that in both cases, o-hydroxyphenol, 4-methoxyphenol, and $\mathrm{Ph}$ are the most commonly emitted phenolic compounds from the burning of Eucalyptus and Radiata Pine pellets. However, the firewood stove exhibited the largest concentration differences between the compounds compared to the pellet heater; the firewood stove presented o-hydroxyphenol and 4-methylphenol differences of 32 times with respect to $\mathrm{Ph}$, and the pellet heater presented a maximum difference of 2.5 times with respect to $\mathrm{Ph}$.

A point that should be noted is the presence of cresols (methylated phenols). Cresols are highly toxic phenolic derivatives, and their emission occurs due to the burning of firewood and pellets. Phenolic compounds were not detected in the emissions of kerosene stoves.

Then, aiming to find a combustion marker for gasoline, diesel, and the wood and pelletized wood used mostly in Santiago de Chile, we see that Ph would not be a good marker since $\mathrm{Ph}$ is emitted in all of the combustions studied. 2-NPh and 4-NPh represent sources associated with diesel but not the burning of wood. Hydroxylated, methylated and methoxylated phenolic derivatives could represent wood burning both under open and controlled conditions. In light of these results, we propose that o-hydroxyphenol (catechol) is a marker of wood burning due to its presence in all of the combustions studied and its marked difference in the emitted concentration levels.

\subsection{Phenol derivatives in the atmosphere}

In the atmosphere of downtown Santiago, the presence of phenolic compounds is actually associated with two emissions sources: mobile sources and heating sources (COV in the emissions inventory of 2012).

Figure 1 shows the average values for 12 hours during the day and 12 hours during the night in Santiago at an urban site located in the eastern downtown sector. The presence of Phs, nitrophenols, and hydroxy phenols (catechol) indicates the presence of mobile (gasoline and diesel) and heating sources used during the daytime and night-time in June 2015 and June 2016. Figure 1 shows no differences in the night and day hours. In the Santiago atmosphere, PHs, hydroxyl derivatives, methoxy derivatives, methyl derivatives and nitrated derivatives were present, confirming the diversity in both the mobile and fixed emission sources.

This result is somewhat different from that obtained in a field campaign carried out in downtown Santiago during the winters of 2010 and 2011, whereby Phs and nitrophenols were identified and quantified. ${ }^{13}$ Daily profiles were made (an average of every four hours) for $\mathrm{Ph}, 2-\mathrm{NPh}$, and $4-\mathrm{NPh}$, and the three compounds peaked in the $8 \mathrm{a} . \mathrm{m}$. to $12 \mathrm{a} . \mathrm{m}$. period, followed by a sharp decrease in the concentrations. These profiles were compatible with the dominant role of the emissions of vehicles during the peak hours in these years, followed by photochemical elimination after midday. ${ }^{13}$ Until 2012, the dominant sources in Santiago were those from vehicles. However, according to the last study of the sources in Santiago, heating has increased its participation, and home heating has switched from liquefied petroleum gas (LPG) to firewood and kerosene. ${ }^{46}$ Furthermore, early morning emissions from the burning of biofuels may contribute to these maximum concentrations. It must be considered that the low early morning temperatures imply maximum heating with biomass combustion and high concentrations of particles and/or gas phase pollutants due to temperature inversion at the ground level.

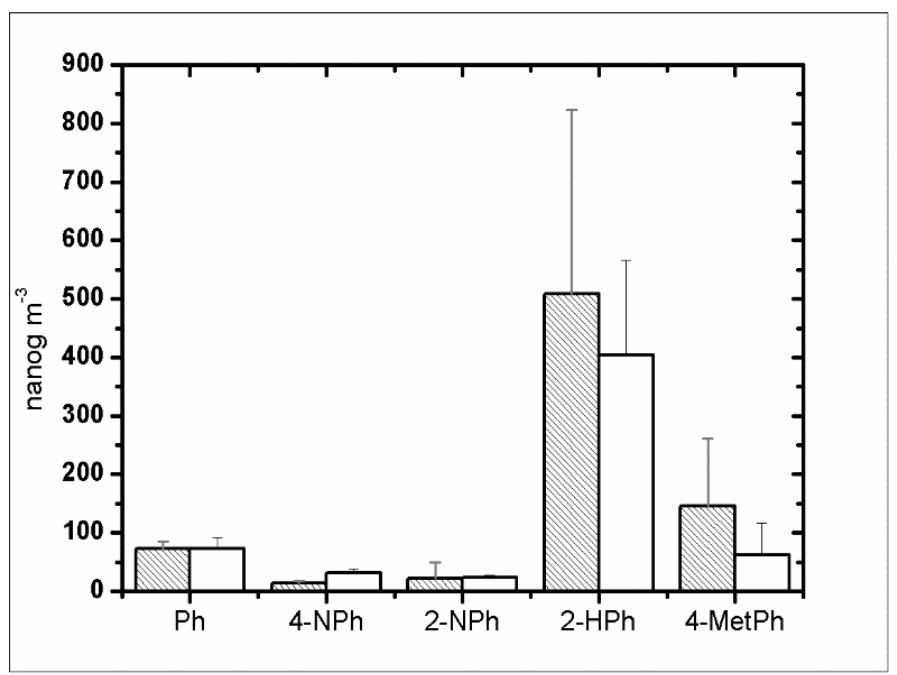

Figure 1. Average values for 12 hours during the day and 12 hours during the night of Phenolic derivatives in Santiago ( $\square$ nighttime, $\square$ day time) 
In a seasonal study conducted during the summer of 2014 and the winter of 2015 (Figure 2), the concentration levels of o-hydroxyphenol (catechol), which is the most abundant $\mathrm{Ph}$ derivative in the air of Estación Central, were evaluated. This site corresponds to a primary emission location dominated by mobile sources. Nevertheless, high values were found during the night-time in the winter using average values every three hours. Two factors can account for the profile difference. If only the daytime and night-time hours are compared, we would be averaging maximum and minimum values without giving more precise information, which is why a five-day hourly average would show the behaviour of catechol in detail, as this is a phenolic derivative associated with firewood burning. The difference in the concentrations of these measurements is rationalized as a result of the decrease in the height of the mixing layer in the winter and the source change from mobile sources to firewood burning sources during the last four years. Santiago and Chile in general, has changed its heating energy sources, so the atmospheric catechol measured in downtown Santiago is strongly associated with firewood burning or the use of firewood heating in the city of Santiago. This finding is supported by analysing the inventory of emissions in Santiago, where more than $50 \%$ of the COV is attributed to residential emissions. ${ }^{48}$

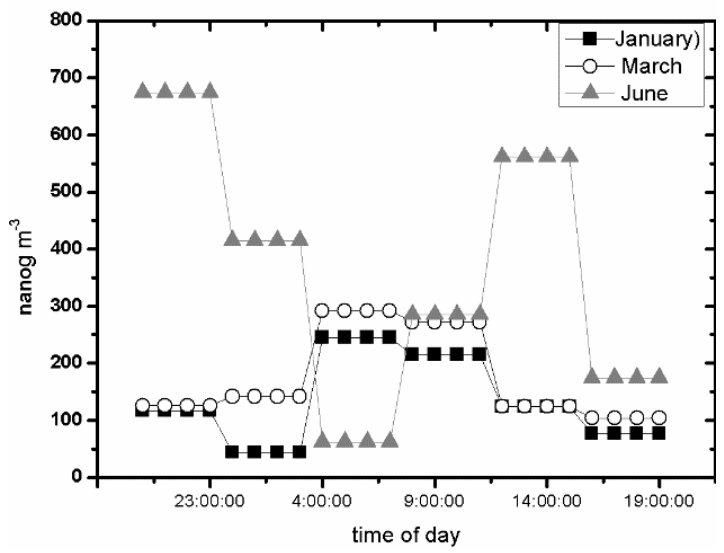

Figure 2. O-hydroxyphenol levels in January, March, and June

The use of phenolic compounds as tracers of combustion sources in the city of Santiago is possible because the study shows selectivity and a dependence of the emissions from the exhaust pipes on the types of fuels and engines and a dependence on the type of firewood used. The presence of 2-NPh and 4-NPh has been determined with the use of diesel fuel. Catechol, methoxyphenol, and cresol are associated with the burning of wood in heating devices.

The average 12-hour concentrations of the phenolic derivatives present in the atmosphere during the night-time and daytime are similar, showing that during the day or the night, there is no formation of these compounds. The emission source is primary. This phenomenon is clearly observed if we compare the profiles of carbon monoxide and catechol. The correlation is high, showing that both measured compounds have a primary emission source, as shown in Figure 3.

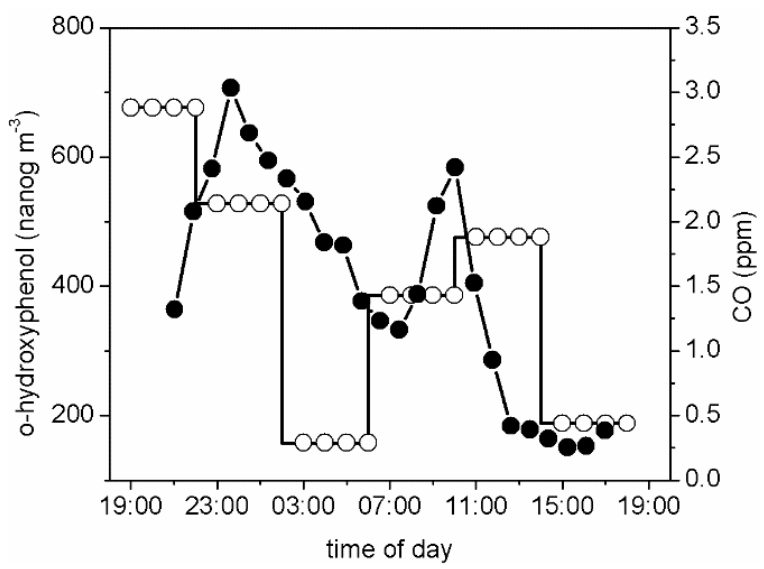

Figure 3. Daily profiles of carbon monoxide and o-hydroxyphenol
Important data are reported in a very specific study by Vasquez $(2016)^{49}$, who found that the emissions from the burning of biomass, such as wood and pellets, were photolysed using a photochemical camera by UV-A irradiation with an intensity similar to that received in Santiago in the month of October (spring). The results of this study did not show an important degree of photolysis or formation of nitrated derivatives of secondary origin, so the presence of these compounds clearly points to the appearance of a new emission source, which is firewood burning in eastern downtown Santiago, even though the radiation used was higher than that in the months of autumn and winter in Santiago.

\section{CONCLUSIONS}

The presence of $\mathrm{Ph}$ derivatives in Santiago atmosphere indicates the existence of mobile sources (daytime) and the use of firewood (night-time). The presence of 2-NPh and 4-NPh derivatives in the air would be strongly associated with the use of mobile sources that use diesel. In contrast, catechol is associated with the burning of wood for house heating.

The type of firewood influences the proportions of emitted Ph derivatives. However, regardless of the kind of wood used, catechol (o-hydroxyphenol) is emitted in high proportions.

\section{ACKNOWLEDGEMENTS}

We are grateful for the financial support of Fondecyt under project 1170456 and Basal Funding for Scientific and Technological Centers under project FB0807

\section{REFERENCES}

1. Schwarzenbach R. P., Stierti R., Folsom B. R., Zeyer J. Environ. Sci. Technol. 22, 83-92, (1988.

2. Cecinato A., Di Palo V., Pomata D., Tomasi Sciano M. C., Possanzini M. Chemosphere. 59, 679-683, (2005).

3. Morville S., Scheyer A., Mirabel P., Millet M. Environ. Sci. Pollut. 13, 8389, (2006)

4. Bishop and Mitra S. Anal. Chim. Acta. 583, 10-14, (2007).

5. Delhomme O., Morville S., Millet M. Atmos. Pollut. Res. 1, 17-22,(2010)

6. Luttke, J., Levsen K., Acker K., Wieprecht W., Moeller D. Int. J. Environ. An. Ch. 74, 69-89, (1999)

7. Leuenberger Ch., Cuzuczwa J., Tremp J. Giger, W.) Chemosphere 17, 511-515, (1988

8. Schuessler W., Nitschke L. Chemosphere 42, 277-283, (2001)

9. Schummer C., Groff C., Al Cami J., Kaber F., Millet M. Sci. Total Environ. 407, (2009)

10. Geisler A., Scholer H.F. Water Res. 28, 2047-2053, (1994).

11. Grynkiewic Z. M., Polkowska Z., Kot-Wasik A., Namiesnik J. Polish J. Environm. Studies 11, 85-89, (2002)

12. Richartz H., Rheischl A., Trautner F., Hutzinger O. Atmos. Environ. 24, 3067-3071, (1990)

13. Rubio M.A., Lissi E., Herrera N., Perez V., Fuentes N. Chemosphere 86, 1035-1039, (2012

14. Harrison M. A., Barra S., Borghesi D., Vione D., Arsene C., Olariu R. Atmos. Environ. 39, 231-248, (2005).

15. Bohm J.H., Feltes J., Volmer D. and K. Levsen. J. Chromatogr. 478, 399407, (1989)

16. Grosjean D. Sci. Total Environ. 100, 367-414, (1991).

17. Michalowicz J. and Duda W. Pol. J. Environ. Stud. 16, (3), 347-363, (2007)

18. Heal M., Harrison M., Cape J. N. Atmos. Environ. 41, 3515-3520, (2007)

19. Vione D., Belmondo S., Carnino L. Environ. Chem. Lett. 2, 135-139, (2004)

20. Patnaik P., Khoury J. Water Res. 38, 206-210, (2004)

21. Luttke J., Scheer, V., Levsen K., Wunsch G., Cape, J., Hargreaves R., Storeton-West R. Acker K., Wieprecht W., Jones B. Atmos. Environ. 31 2637-2648, (1997)

22. Vione D. MaurinoV., MineroC., VincentiM., Pelizzeti E. Chemosphere 44, 237-248, (2001)

23. Kahnt A., Behrouzi S., Vermeylen R., Safi Shalamzari M., Vercauteren J., Roekens, E., Claeys M., Maenhaut W. Atmos. Environ. 81, 561-568, (2013)

24. Nojima K.T., Kawaguchi A., Ohya T., Kanno S., Hirobe M. Chem. Pharm. Bull. 31, 1047-1051, (1983) 
25. Tremp J., Mattrel S., Fingler S., Giger W.) Water Air Soil Poll. 68, $113-$ $123,(1993)$

26. Perrone M., Carbone C., Faedo D., Ferrero L., Maggioni A., Sangiorgi G., Bolzacchini E. Atmos. Environ. 82, 391-400, (2014)

27. Jolleys, M. H., Coe, G. Mc Figgans, G. Capes, J. Allan, J. Crossier, F. Williams, G. Allen, K. Bower, J. Jimenez, L. Russell, M. Grutter, D. Baumgardner. Environ. Sci. Technol. 46,(24), 13093-13103,(2012)

28. Roldan P., E. Swietlicki, A. Massling, A. Kristensson, J. Londahl, A. Erikssson, J. Pagels, S. Gustafsson. Atmos. Chem. Phys., 11, 5897-5915, (2011)

29. Yee L.D., Kautzman K.E., Loza C.L., Schiolling K.A., Coggon M.M., Chhabra P.S., Chan M.N., Chan A.W.H., Hersey SD.P., Crounse J.D., Wennberg P.O., Flagan R.C., Seinfeld J.D. Atmos. Chem. Phys, 13, 80198043, (2013)

30. Roy M., A. Dutta, K. Corscadden. Applied Energy, 108, 298-307,(2013).

31. Johansson L., B. Lokner, L. Gustavsson, D. Cooper, C. Tullin, A. Potter Atmos. Environ. 38, 4183-4195, (2004).

32. Schmidl, C., M. Luisser, E. Padouvas, L. Lasselsberger, M. Rzaca, C. Ramirez-Santa Cruz, M. Handler, Ge Peng. Atmos. Environ. 45, 74437454, (2011)

33. Yu, L.D., Wang, G.F., Zhang, R.J., Zhang, L.M., Song, Y Wu, B.B., Li, X.F., An, K. and Chu, J.H. Aerosol Air Qual. Res. 13, 574-583. (2013).

34. Kjallstrand H., Olsson M. Biomass Bioenerg. 27, 557-561, (2004)

35. Mitchell E., A. Lea-Langton, J. Jones, A. Williams, P. Layden, R. Johnson. Fuel Process Technol. 42, 113-123, (2016)

36. Neuman J., D. Parrish, M. Trainer, T. Ryerson, D. Holloway, J. Nowak, A. Swanson, F. Flocke, J. Roberts, S. Brown, H. Stark, R. Sommariva, A. Stohl, R. Peltier, R. Weber, Wollny A, Sueper G, Fehsenfeld F. J. Geophys.Res-Atmos. 111, D23, (2006)
37. Yuan B., Liggio J., Wentzell J., Li S-M., Stark H., Roberts J., Gilmann J., Lerner B., Warneke C., Li R., Leithead A., Osthoff H D., Wild R., Brown S. S., de Gouw J. A. Atmos.Chem. Phys. 16, 2139-2153, (2016)

38. Belloni R., Barletta B., Bolzacchini E., Meinardi S., Orland M., Rindone B. J. Chromatogr. A. 846, 277-281, (1999)

39. Gramsch E, Papapostolou V, Reyes F, Vásquez Y, Castillo M, Oyola

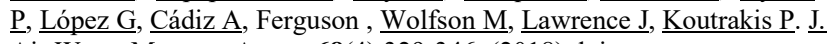
Air Waste Manage. Assoc. 68(4):329-346, (2018) doi: 10.1080/10962247.2017.1386600

40. Simoneit B. Appl. Geochem., 17. 129-162, (2002)

41. Taiz L., Zeiger E., Plant physiology 4th ed. Sunderland, M A Sinaur Associates Inc. (2006)

42. Sheesley R.J., Schauer J., Chowdhury Z., Cass G., Simoneit B.R.T. J. Geosphys. Res. 108, 9, 4285-4299, (2003)

43. Hedberg, E., Kristensson, A., Ohlsson, M., Johansson, P., Swietlicki, E., \& Vesely, V. W. Atmos Environ, 36, 4823-4837, (2002)

44. Hennigan, C. J., Miracolo, M. A., Engelhart, G., May, A. A., Presto, A. A., Lee, T. Robinson, A. L. Atmos. Chem. Phys. 11, 7669-7686, (2011)

45. Schmidl, C., Markus, L., \& Padouvas, E. Atmos Environ, 45, 7443-7454, (2011)

46. Mendenhall, W.; Beaver, R.J.; Beaver, B.M. (2009). Non parametric statistics. In W. Mendenhall, R. Beaver, \& B. Beaver, Introduction to probability and statistics. (13 ed., Vol. 15, 630-637. Belmont, CA

47. González, R. B. Área de Estadística, Facultad de Ciencias Económicas y Empresariales. 2006).

http://byrong.50g.com/estadistica/estadap/shapiro_wilks_byrong.pdf. May, 2011.

48. Gramsh E. (2014) www. inventario-de-emisiones-RM_usach_2014.

49. Vásquez Y., Doctoral Tesis. Conicyt 2016. Systematic study of the emissions associated with biomass burning. $\mathrm{N}^{\circ} 21120705$. 